\title{
El conflicto entre realismo y abstracción en el ámbito del arte español como reaparición de la Querelle des Anciens et des Modernes
}

\author{
The conflict between realism and abstraction in the field of \\ spanish art as an iteration of la Querelle des Anciens et des \\ Modernes
}

\author{
DANIEL VILLEGAS \\ Departamento de Artes y Diseño. Universidad Europea de Madrid \\ daniel.villegas.glez@gmail.com
}

Recibido: 8 de octubre de 2014

Aprobado: 15 de enero de 2015

\section{Resumen}

Partiendo del modelo de análisis propiciado por el estudio de las condiciones en las que se produjo la Querelle des Anciens et des Modernes del siglo XVII, se examina el caso de la confrontación entre realismo y abstracción, que se produjo, en el contexto del arte español, en la década de los noventa del siglo XX. Se establecen conexiones con otros conflictos estéticos que son considerados parte de una genealogía cuyo antecedente más nítido se puede situar en la referida querella, como son el enfrentamiento entre realismo y abstracción en el ámbito artístico estadounidense, acaecido en los años cincuenta del pasado siglo, y la polémica, más reciente, en torno al pluralismo y el fin del arte.

Palabras clave: realismo, abstracción, Querelle des Anciens et des Modernes, pluralismo, fin del arte.

Villegas, D. (2016): El conflicto entre realismo y abstracción en el ámbito del arte español como reaparición de la Querelle des Anciens et des Modernes. Arte, Individuo y Sociedad, 28(1) 23-40

\footnotetext{
Abstract

Based on the analysis model favored by the study of the conditions in which the seventeenth century Querelle des Anciens et des Modernes took place, we examine the case of confrontation between realism and abstraction, which occurred in the context of Spanish art in the nineties of the twentieth century. Connections are established with other aesthetic conflicts which are considered part of a genealogy whose most explicit antecedent could be placed in the before mentioned complaint, such as the confrontation between realism and abstraction in the American art scene, which occurred in the fifties of the last century, and the more recent controversy on pluralism and the end of art. Keywords: realism, abstraction, Querelle des Anciens et des Modernes, pluralism, end of art.
} 
Sumario: 1. Antecedentes de la Querella. La conformación de un modelo de conflicto, 1.1. La Querelle des Anciens et des Modernes, 1.2. El triunfo del modelo de lo moderno como búsqueda incesante de la novedad en lo artístico, 1.3. La Querella de la abstracción y el realismo en el contexto del arte estadounidense, 1.4. ¿La disolución de la dialéctica de la Querella? La disputa en torno al pluralismo, 2. La Querella del realismo y la abstracción en el contexto español, 2.1. Las condiciones de la Querella, 2.2. El punto álgido de la Querella. 2.3. El final de la Querella. Referencias.

\section{Antecedentes de la Querella. La conformación de un modelo de conflicto}

El proyecto de la modernidad se caracterizó, fundamentalmente, por la confrontación con la noción de tradición. Un proceso marcado, según Peter Sloterdijk, por el desenmascaramiento de los elementos centrales del sistema de creencias heredado del Antiguo Régimen (Sloterdijk, P. 2003), lo que supuso la inauguración de la moderna cultura de la sospecha. Tal circunstancia puede rastrearse, particularmente, en el desarrollo de la modernidad estética que estableció una agenda, sobre todo a partir del siglo XIX, basada en la desarticulación de un esquema de dependencia de lo clásico en favor de un mecanismo de innovación permanente en la definición de lo artístico. Este fenómeno se encontraría situado en el imperativo moderno de voladura de la tradición, entendida ésta como un conjunto de supersticiones. Desde aquellos tiempos, como sostiene Fredric Jameson,

(...) la demolición ha definido la vocación del intelectual moderno desde que el antiguo régimen tendió a identificar su misión con la crítica a las instituciones e ideas establecidas (...) Es una figura que parecía presuponer la omnipresencia del Error, definido diversamente como superstición, mistificación, ignorancia, ideología de clase e idealismo filosófico (o «metafísica»), de tal manera que eliminar ese Error por medio de operaciones de desmitificación dejaba un espacio en el que la ansiedad terapéutica iba de la mano con la acusada autoconciencia y reflexividad en varios sentidos, si es que no, ciertamente, con la Verdad como tal (Jameson, F. 2000, p. 25).

La necesidad moderna de cuestionar los valores que la tradición había legado, para así tener acceso a la Verdad, tendrá enormes consecuencias en la construcción de un sistema artístico que, no sin resistencias, logrará imponer una lógica fundamentada, de consuno con el desarrollo de la historia como institución guía de la sociedad, en la perfectibilidad del arte como proceso progresivo, correspondiendo unas formas artísticas definidas a un tiempo histórico concreto, o lo que es lo mismo un arte históricamente mandatado. Se clausura, de este modo, su dependencia respecto de la tradición, quedando las expresiones artísticas asociadas con ésta, siguiendo las tesis hegelianas, fuera del linde de la historia, en el territorio del Error. Es posible situar como fenómeno inaugural de este tipo de lógica en la Querelle des Anciens et des Modernes, que supondrá no sólo la contienda más importante que fijará una nueva forma de entender el desarrollo de lo artístico sino el modelo que definirá, con posterioridad, el devenir del arte hasta tiempos recientes, donde esta dialéctica parece haberse disuelto. Refiriéndose al debate entre el realismo y el modernismo, que tuvo lugar en la década de los treinta del pasado siglo, en el marco de la efectividad política del arte, Jameson afirma que con la Querelle des Anciens et des Modernes es 
cuando "(...) por primera vez, la estética se encuentra cara a cara con los dilemas de la historicidad" (Jameson, F. 2009, p. 190).

El fenómeno enunciado por Jameson será, precisamente, el fundamento que articulará el patrón interpretativo de los diferentes conflictos que, a partir de la Querelle originaria, se producirán a lo largo del proceso de implantación de la modernidad estética. Si bien es cierto que cada uno de los episodios que aquí se analizan gozará de sus particularidades, se puede establecer una genealogía basada en la reaparición de cierto tipo de argumentos vinculados a una forma concreta de tratarse con la historia desde el ámbito de lo artístico. De este modo si en la Querelle des Anciens et des Modernes se enfrentaron las nociones de una modernidad -que confiaba en el progreso de las artes y, en consecuencia, en la existencia de un arte históricamente mandatado- con la de una tradición que expresaba la superioridad de los antiguos, en lo sucesivo se repetirá, adoptando otras formas, un esquema narrativo semejante basado en una lectura concreta de la historicidad, especialmente en lo relativo a quienes, en enfrentamientos posteriores, asumirán la función de defensa de lo moderno. Así, se puede encontrar en el contexto estadounidense de la querella entre el realismo y la abstracción, una postura de defensa de la modernidad del expresionismo abstracto entendida como culminación de un proceso histórico de perfectibilidad artística que supone, al menos en opinión de Clement Greenberg (Greenberg, C. 2002), la demostración de la obsolescencia de ciertas formas artísticas asociadas al realismo, que hundían sus raíces en la tradición. También pueden hallarse posiciones enfrentadas en la defensa de esta estética de raigambre humanista que conformaran un frente, hasta cierto punto, conservacionista de una herencia proveniente de una idea especifica de antigüedad matizada, en este momento concreto, con una apelación a la necesidad de coexistencia, en el panorama artístico, de una pluralidad de expresiones artísticas. Será justamente la noción de pluralismo sobre la que se fundará el enfrentamiento hermenéutico, que se producirá en tiempos más recientes entre autores como Hal Foster (Foster, H. 1995), que consideran el arte como un fenómeno históricamente situado, con quienes como Arthur C. Danto (Danto, A. C. 1999) sostienen que con la emergencia de un escenario pluralista, en el que se suspenden las condiciones establecidas por el sistema histórico moderno, el modelo excluyente propio de la Querelle quedaría inhabilitado y, por último, con los que se sitúan en el territorio esencialista, ejemplarizado en el caso de Donald Kuspit (Kuspit, D. 2006), para los que debería existir una pervivencia de ciertos aspectos de la tradición en el arte actual que garantizara una salida a lo que consideran una situación de decadencia. Todos estos antecedentes dotarán de argumentos al conflicto que se produciría en la década de los noventa del siglo XX, en el contexto artístico español, entre el realismo y la abstracción, asunto central del presente artículo, donde, de modo un tanto extemporáneo, aparecerán de nuevo las posturas del bando de los modernos insistiendo en la noción excluyente de un arte históricamente mandatado y la de los antiguos que, ya sin la fuerza argumental de la querella original, defenderán la opción realista desde la idea de respeto a la pluralidad, que ya se atisbó en el conflicto de la década de los cincuenta. 


\subsection{La Querelle des Anciens et des Modernes}

La Querella hunde sus raíces en la aparición del término moderno, tal como afirma Jean Clair, allá por el siglo VI en Casiodoro (Clair, J. 1998, p. 23). Del mismo modo, señala Hans Robert Jauss que pese a que, el término moderno, modernus, es de origen latino tardío, la problemática en torno a su contraste con la Antigüedad tiene su génesis en una tradición literaria anterior que se remonta a la cultura clásica (Jauss, H. R. 1976, pp. 14-15). Tanto Jauss como Marc Fumaroli han desarrollado la genealogía de la oposición entre antiqui y moderni desde la Edad Media, pasando por el Renacimiento con Petrarca, hasta la gran Querella del siglo XVII, basada en una cierta convivencia de ambas nociones, hasta su enfrentamiento excluyente.

El momento culminante de dicho fenómeno se encontrará en la lectura del poema El siglo de Luis el Grande de Charles Perrault en la Académie Française en su sesión del 27 de enero de 1687. Su propuesta trataba de romper con la antigüedad literaria grecolatina en pos de una modernidad cristiana. Tal planteamiento bien podría, como sostiene Fumaroli, aplicarse al territorio de lo artístico (Fumaroli, M. 2008, p. 41). La Querelle des Anciens et des Modernes ayuda a consolidar, de algún modo, la percepción de la historia como progreso y superación, en concordancia con la importancia que en aquel tiempo iba adquiriendo la ciencia histórica y que medio siglo después daría origen al Sattelzeit, definido por Reinhart Koselleck (Koselleck, R. 2004). Los antecedentes directos de la Querella francesa se fueron gestando lentamente, desde aproximadamente mediados del siglo XVI, con la adopción de posturas contrapuestas que, postreramente, se convertirían en los bandos enemigos de los Modernes y los Anciens.

La ofensiva lanzada por Perrault, desde el bando de los Modernos, fue contestada de inmediato por los Antiguos, que defendían la belleza y la verdad moral de las obras maestras antiguas (Fumaroli, M. 2008, p. 175). La respuesta estuvo encabezada por Nicolas Boileau-Despréaux, que defendía una autonomía literaria fundada en la legitimidad de la Antigüedad como origen de verdades esenciales atemporales, no aceptando como fuente y criterios del juicio moral y estético la pura y simple contemporaneidad (Fumaroli, M. 2008, pp. 158-159).

La Querella se extenderá a Inglaterra de la mano de Jonathan Swift. Éste publica, en 1697, La Batalla de los libros (Swift, J. 2005) que se convertirá en la obra de referencia entre los Antiguos y dotará a la Querella de su imagen paradigmática, extraída de la fábula de Montaigne (adoptada de Horacio y Erasmo), sobre las abejas, que servirá para desarrollar las conclusiones de dicha obra y, finalmente, se tendrá por el manifiesto más célebre a favor de las posiciones de los Antiguos. Las abejas, productoras de un exquisito manjar fruto de la destilación de lo mejor de la historia cultural (Fumaroli, M. 2008, p. 12), corresponderían al bando de los Antiguos mientras que los Modernos serían simbolizados por las arañas, entendidas como metáfora de lo autorreferencial (Fumaroli, M. 2008, p. 250).

El criterio de los Antiguos prevalecerá, finalmente, gracias al favor de Luis XIV hacía éstos. La sublime cámara de Boileau y Racine se impuso, como puede colegirse del nombramiento de ambos poetas como historiadores reales, además de otras distinciones y atenciones que les dispensó el monarca. Así la hegemonía de los Antiguos se prolongó a lo largo del siglo XVIII, hasta la entrada en escena de 
Diderot y de los filósofos de las luces quienes volverán a resucitar los argumentos contra el culto a la Antigüedad. Esta situación se extenderá al terreno del arte. Con la muerte de Charles Lebrun, en 1690, terminará el dominio de la Academia por parte de los Modernos, deslizándose el arte del siglo XVIII hacia la postura de los Antiguos gracias a la entrada en la institución de Jules Hardouin-Mansart, Charles de La Fosse, Roger de Piles y del conde de Caylus, quien se alzó como el gran reformador de la Academia de Pintura y Escultura entre 1747 y 1764.

Fumaroli sostiene, en cualquier caso, que la Querelle des Anciens et des Modernes naufragó junto con el Antiguo Régimen con el advenimiento de la Revolución Francesa que produjo un cambio radical en el marco regulador, en términos sociales, políticos y culturales. Clair indica que la idea de lo moderno, en torno a 1830, se transformará de manera irreversible, estableciéndose su predominio basado la novedad, en "(...) la idea de búsqueda incesante y febril de lo nuevo exclusivamente, y su exaltación (...)" (Clair, J. 1998, p. 24).

\subsection{El triunfo del modelo de lo moderno como búsqueda incesante de la novedad en lo artístico}

El nuevo concepto de la actualidad, propio de la modernité, encontrará su definición más clara en Charles Baudelaire, y más concretamente en su texto El pintor de la vida moderna de 1859, donde introducirá la idea de nouveauté. Una novedad asociada a la moda que implicará la desactivación de la lógica de la Querella, gracias al planteamiento de una modernidad que no se opone a ningún pasado determinado, y mucho menos a la Antigüedad. Baudelaire rechazará de plano la dependencia de ésta como principio de autoridad de lo bello en lo actual:

¡Ay de aquel que estudia en lo antiguo algo más que el arte puro, la lógica, el método general! Por dedicarse demasiado a él, pierde la memoria del presente, abdica del valor y de los privilegios proporcionados por la circunstancia; porque casi toda nuestra originalidad viene del sello que el tiempo imprime en nuestras sensaciones (Baudelaire, C. 1995, p. 94).

Funda, de este modo, el nuevo mecanismo moderno, en consonancia con el papel que la ciencia histórica había empezado a desempeñar, que vendrá a sustituir al de las querellas anteriores pero que, en cierto modo, operará como origen de los posteriores litigios que se producirán en el contexto de las tensiones generadas por la necesidad constante de novedad, propia de este concepto de modernidad, demandada por las diversas sensibilidades asociadas a las distintas épocas que se irán sucediendo. La sucesión acelerada de movimientos artísticos, que se pretendían todos poseedores de la sensibilidad de la época y cuya duración era cada vez más corta, constituirá la lógica cultural de una modernidad autoconsciente desde el punto de vista histórico y que ocasionaría más de un conflicto, de entre los que se puede citar el litigio protagonizado, a partir de la década de los cincuenta del siglo XX en Estados Unidos, por el realismo frente al expresionismo abstracto. 


\subsection{La Querella de la abstracción y el realismo en el contexto del arte estadounidense}

El proceso de ascenso y conformación del expresionismo abstracto, como referente fundamental del arte norteamericano durante la época de postguerra, tiene su origen en las dos décadas inmediatamente anteriores. Más allá de la instrumentalización de esta estética como propaganda política, en los años cuarenta del siglo XX, como representación de los valores de la triunfal democracia americana, existía ya, desde la década de los treinta, una sensación entre los diferentes agentes que conformaban la realidad artística del momento, de encontrarse ante un nuevo, y fundamental, estadio del arte, amparándose en una lógica historicista de progreso de filiación hegeliana. Entre éstos "Greenberg es un caso interesante para ser examinado bajo esta luz. En 1939 vio la abstracción como históricamente inevitable: la abstracción era, como (...) argumentó en «Towards a Newer Laocöon», un «imperativo [que] viene de la historia»." (Danto, A. C. 1999 , p. 134). Clement Greenberg en su artículo Abstracto y representacional de 1954 afirmaría “(...) que lo mejor del arte abstracto sea también lo mejor del arte de nuestro tiempo. Y si lo abstracto es realmente empobrecimiento se ha convertido en necesario para el arte que importa" (Greenberg, C. 2002, p. 157).

Indicará, así, la inevitabilidad del arte abstracto en el contexto del devenir de la cultura moderna que, como consecuencia de la determinación histórica, deja en los márgenes las opciones representacionales producidas en esta época. Estos planteamientos habían sido ya expuestos, en cierto modo, en Hacia un nuevo Laocoonte donde definiría la idea de "medio", concepto que se convertirá en referencia central de su teoría, entendido como las condiciones específicas que distinguen una forma expresiva de otra. De la aceptación de esas limitaciones dependerá la pureza artística de una obra de arte en particular. Las condiciones en relación con la pintura son tres, pero quedará resumida en la planitud (flatness). Desde esta perspectiva, el desarrollo del arte moderno se ha basado en una progresiva aceptación y autoconsciencia de estas condiciones, que definen el "medio", oponiéndose así los planteamientos pictóricos tradicionales que se caracterizaron por la invisibilización de las mencionadas limitaciones. Este desarrollo culminará con la abstracción, y más concretamente con el expresionismo abstracto, que tomará estas restricciones como elemento básico de referencia de su práctica. En este sentido, los planteamientos realistas quedaban excluidos de la lógica del devenir histórico. De facto el planteamiento de Greenberg dejaba fuera del marco de las exigencias estéticas de la época el trabajo de los artistas que se incluían en el espacio de lo representacional (Greenberg, C. 2002, p. 158).

Este contexto, caracterizado por la creciente importancia y presencia pública de la abstracción, especialmente en las instituciones de arte moderno, generó una airada reacción por parte de los pintores realistas, con Edward Hopper a la cabeza, quienes empezaban a sentirse fuera del marco excluyente impuesto por una visión de la historia progresiva, donde el futuro pertenecía a la abstracción. Quedando desplazados, situados en el margen de la obsolescencia, del progreso del arte impuesto por el automovimiento histórico.

La reacción del grupo de los realistas se organizó alrededor de diversas plataformas, entre las que destaca la fundación, en 1953, de la revista Reality. A journal of Artist opinion, editada, entre otros, por Hopper. En su primer número se publicó una declaración firmada por cuarenta y seis pintores realistas en defensa de la opción 
estética que representaban (Avery, M. et al. 1953,p.1), frente a lo que percibían como el imperio de la abstracción. Del mismo modo, utilizaron otros canales de protesta como la campaña contra la política museística del MoMA, incluyendo una carta dirigida a esta institución y publicada por el referido medio de comunicación (Avery, M. et al. 1953, p.2). En definitiva se trataba de una reivindicación ante lo que se consideraba, ya en los años cincuenta, el mainstream artístico. Se constituyó un fenómeno de contestación, que recuerda la posición del bando de los Antiguos en la celebérrima Querella, frente a una modernidad entendida en términos de autoconsciencia pero, esta vez, añadiendo a los beligerantes argumentos humanistas más clásicos (Sharrer, H. 1953, p. 4) otros provenientes de una incipiente estirpe pluralista: "todo arte es una expresión de la experiencia humana. Todas las posibilidades del arte han deben ser exploradas para ampliar esa expresión" (Avery, M. et al. 1953, p.1). No existió, en el contexto de la abstracción, una respuesta homologable a la de los Modernes salvo la contestación exculpatoria por parte de la dirección del MoMA a la mencionada carta donde se contradecía, con datos concretos, la acusación de falta de representación del realismo en esta institución (d'Harnoncourt, R., Barr, A. H. \& Ritchie,A. C. 1953, 24 de abril). La inexistencia de confrontación por parte de los defensores del expresionismo abstracto, quizás, fue debida a que la lógica moderna, que imponía una constante renovación y actualización de las formas artísticas, gozaba de tal implantación que, durante la época dorada del expresionismo abstracto, su hegemonía estaba fuera de cualquier discusión, pese a los conatos de reacción del grupo de los realistas. En cualquier caso, el mecanismo de la inexorable obsolescencia de cualquier posición estética terminaría afectando, del mismo modo, al expresionismo abstracto, cuyas perspectivas serían sometidas a un duro examen crítico a partir de la década de los setenta. Sostiene Danto que el final de este conflicto, en la década de los sesenta, se produjo por causas exógenas al mismo con la aparición del pop (Danto, A. C. 1999, p. 135).

\section{4. ¿La disolución de la dialéctica de la Querella? La disputa en torno al pluralismo}

A finales de la década de los setenta, del siglo pasado, se producirá un corte en la narración de la historia del arte progresiva que ya pareció anunciarse con la aparición de los movimientos tardomodernos y neovanguardistas de las dos décadas anteriores. Un planteamiento de vuelta a ciertos estilos y procedimientos históricos comprometieron la idea de progreso que, de una manera más o menos ininterrumpida, había articulado el desarrollo, al menos desde un planteamiento historiográfico, del arte moderno. Algunos quisieron ver en tal circunstancia, no sin provocar una importante controversia, el agotamiento de una dialéctica que había sido el motor de desarrollo de aquél y el inicio de una nueva era artística donde las querellas ya no tendrían sentido porque ya todo estaría permitido, incluso revisitar el pasado o si se quiere la tradición, en un marco cultural pluralista.

El conflicto en torno al pluralismo hunde sus raíces en otra polémica, de orden historiográfico de estirpe hegeliana, aparecida en la década de los ochenta sobre el fin de la historia y, por extensión, del arte, que encontraría, sin duda, acomodo en el ámbito de la teoría postmoderna en lo relativo a la incredulidad frente a cierta noción de progreso vinculada a la deslegitimación de los metarrelatos legitimadores 
de la sociedad moderna (Lyotard, J. F.1998, pp. 73-78) y a la emergencia de una lógica cultural postmoderna que se desentendía de la historicidad (Jameson, F. 1998, pp. 9 y 290-293). En lo artístico, la invocación al marco pluralista estará ligada, en cierta medida, al desmantelamiento del concepto moderno de movimiento histórico, en su idea fundamental de progreso y perfectibilidad, situando el discurso de sus defensores en la órbita, salvando las evidentes distancias históricas y culturales, de los Antiguos de la célebre Querella.

Desde mediados de los años ochenta, Danto advirtió de la aparición del espacio pluralista dentro del contexto del fin del arte y del advenimiento de una época posthistórica. En su análisis sobre tales circunstancias, Danto adoptará los principios de la filosofía de la historia de Hegel, en relación con su polémica tesis del arte como algo pretérito y terminado: "considerado en su determinación suprema, el arte es y sigue siendo para nosotros (...) algo del pasado" (Hegel, G. W. F. 1989, p. 14). Sin embargo, esto según Danto no quiere decir que ya no se produzca arte en el período posthistórico, “(...) sino que la historia del arte, estructurada narrativamente, había llegado al final." (Danto, A. C. 1999, p. 139). La narrativa que llega a su final con la llegada de la época posthistórica, a la que se refiere Danto, es la que originó el concepto de arte histórico surgido en el siglo XIV. La etapa final de esta era, la edad de los manifiestos, estuvo caracterizada por "(...) cierto dogmatismo e intolerancia" (Danto, A. C. 1999, p. 66). Este marco excluyente finalizó hacia 1964 cuando “(...) emergió la verdadera forma de la pregunta: «Qué es arte»" (Danto, A. C. 1999, p. 66). En este punto se iniciaría la era posthistórica caracterizada por el pluralismo, que acaba con la lógica de progreso y oposición de las diversas opciones estilísticas que habían marcado el desarrollo anterior del arte. Estos tres períodos, en una lectura más o menos forzada, corresponden en opinión de Danto al desarrollo histórico propuesto por Hegel en sus Lecciones sobre Filosofía de la Historia Universal. Con el fin del arte quiere decir que el marco excluyente del historicismo ha terminado y los conflictos y querellas por la hegemonía han quedado superados por el acceso a un nuevo espacio para la libertad artística.

Donald Kuspit, de acuerdo con Danto sostendrá la idea del agotamiento del concepto histórico de arte. En sus tesis, desarrolladas en su libro de 2004 El fin del arte, afirma que se ha llegado a tal situación debido a que el arte ha perdido su carga estética, convirtiéndose en postarte, recogiendo el término acuñado por Allan Kaprow. Sitúa el origen de la desvalorización de lo estético en las prácticas artísticas de Marcel Duchamp y Barnett Newman.

La pérdida de la autonomía estética indica, según Kuspit, que el arte ha llegado a su fin en una lectura ciertamente sesgada. En el contexto del conflicto interpretativo del arte del siglo XX, Kuspit se posiciona como un moderno, a la manera de Picasso o Matisse, que habla desde un conservadurismo, que le sitúa en las coordenadas de esta última querella en el bando de los Antiguos, entendiendo la modernidad como una tradición o, incluso, como nuestra antigüedad. Precisamente amparándose en este tipo de discurso, se articularía el concepto central con el que los comisarios Roger M. Buergel y Ruth Noak, desarrollarían la documenta 12. La situación actual del arte que es percibida, en forma posthistórica, por Danto como un espacio de oportunidades, es tildada de decadente por Kuspit, conceptualizada como postarte, 
cuya preponderancia se basa en la reificación de la relación arte-vida (Kuspit, D. 2006, p. 71). La opción contemporánea que defenderá será la de los Nuevos Viejos Maestros, cuya misión parece ser redimir al arte de su condición postartística y que se caracterizan por ser: "(...$)$ artistas magistrales, reflexivos: humanistas visionarios con un dominio completo de su oficio" (Kuspit, D. 2006, p. 148).

Desde posiciones ideológicas contrarias, Foster se manifestó de modo muy temprano, en 1985, contra el pluralismo que se había ido instalando en la escena artística desde comienzos de la década. Su postura, está vinculada a su rechazo de los argumentos, asumidos por Danto y por Kuspit, asociados al fin de la historia y, consecuentemente, del arte, ligados al cierre en falso de lo histórico, lo dialéctico y lo ideológico. La aparente liquidación de estas instancias encubren la asunción de una ideología economicista, que tiende a presentarse como trasparente y natural. Es decir, como neutral en el terreno de lo político y autoexpresiva en la producción artística. La pretensión de un fin del arte - por el advenimiento de un espacio aconflictivo de convivencia pluralista, en el caso de Danto, o su clausura por decadencia, al apartarse de los valores esenciales ahistóricos que han presidido lo artístico desde su aparición, exceptuando un puñado de buenos artistas que defienden en la actualidad su legado tradicional, atendiendo a los argumentos de Kuspit- contribuye de modo inequívoco a la definición de un espacio artístico reglado por la ley del libre mercado, como sostiene Foster: "Planteada como la libertad de elegir, la posición pluralista juega a favor de la ideología del «mercado libre»; concibe el arte como algo natural, cuando en realidad tanto el arte como la libertad se basan por entero en una serie de convenciones"(Foster, H. 1995, p.82).

La querella en torno al pluralismo y el fin del arte puede ser considerada el último gran conflicto estético del siglo XX, cuyos efectos se extenderán hasta el momento actual, pudiéndose observar la deriva que, los enfrentamientos entre posturas, o ideologías estéticas, ha experimentado desde la Querelle des Anciens et des Modernes hasta el presente. El conflicto ha ido desplazándose cada vez más hacia el terreno hermenéutico, desde sus orígenes de normativización de la producción, y las posiciones que le han conformado tornándose más complejas. Esta querella aparece, a día de hoy, como irresuelta a pesar de la aparente consolidación de un panorama pluralista.

\section{La Querella del realismo y la abstracción en el contexto español}

\subsection{Las condiciones de la Querella}

La Querella entre la abstracción y el realismo en el contexto español tuvo lugar a comienzos de la década de los noventa y se extendió más allá de la mitad de la misma. Tuvo un carácter extemporáneo, lo que conllevó que se produjera sin la nitidez de su predecesora norteamericana. Así, se mezclaron argumentos de diversa índole que no necesariamente respondían al modelo clásico del conflicto entre las dos posturas estéticas enfrentadas. Pueden observarse, por ejemplo, trazas de otras disputas posteriores como son la apelación a un marco exclusivista moderno históricamente mandatado, en el caso de los defensores de la abstracción, frente a las reclamaciones pluralistas de convivencia realizadas por algunos artistas realistas. Del mismo modo, 
el problema no sólo polarizó a los valedores de la abstracción, de una parte, y los del realismo, de otra, sino que también enfrentó esta última opción con las posiciones más expresivas de cierta parte de los neovitalismos hegemónicos en la década anterior. La razón de que esta querella se produjera de forma tan tardía, posiblemente, se debe a la distorsión en el panorama artístico que originó la cultura franquista. Habría que recordar la posición refractaria de gran parte de las instituciones oficiales y de la opinión pública, hacia las prácticas artísticas que se alejaran de la representación tradicionalista, agrupadas indiscriminadamente bajo el calificativo de arte abstracto. Esta situación cambiaría con la operación de propaganda cultural en el exterior, iniciada por Luis González Robles, con la selección de los informalistas del grupo El Paso para representar al Estado español en la XXIX Bienal de Venecia de 1958. A pesar de ciertos síntomas de visibilización que, en el contexto académico y crítico, aparecieron en los años cincuenta, no será hasta la década de los sesenta del siglo pasado cuando las tendencias cercanas a la abstracción, especialmente el informalismo, consigan legitimarse institucionalmente para, con posterioridad, ocupar un lugar de referencia central en la historiografía del arte español contemporáneo.

Desde la aparición de los primeros espacios dedicados a la difusión del arte contemporáneo, el realismo quedó, hasta cierto punto, en los márgenes del discurso historiográfico dominante que se articuló en dichos centros. Así desde su apertura, en 1975, la Fundación Juan March definió una narración histórica del arte español desde la posición del discurso modernista, privilegiando las posiciones de la abstracción y el informalismo. Teniendo en cuenta la escasez de instituciones que en los años setenta existían para la promoción y difusión del arte contemporáneo, el hecho de que las exposiciones y la colección, de la Fundación Juan March, tuvieran la mencionada orientación, pudo generar una cierta percepción, entre los artistas realistas, de marginalización de sus prácticas en el ámbito de la historia del arte español contemporáneo que, en aquellos momentos, apenas se había empezado a construir. De cualquier forma la apuesta de la Fundación Juan March no dejó, en un primer momento, completamente de lado las opciones realistas en la definición del panorama artístico español de la época, aunque paulatinamente fueron perdiendo peso en la agenda expositiva de esta institución.

La inauguración, años después, de la sede madrileña de la Fundación "La Caixa" supondrá un agravamiento en la exclusión del realismo de la narración historiográfica del arte español contemporáneo. Su agenda expositiva se vinculará, en sus primeros momentos, a los neovitalismos que pretendían una reactualización de la figuración. Cuando se observa la casuística expositiva de la fundación, se encuentra la nula presencia del realismo en sus exposiciones, en oposición al apoyo de las tendencias figurativas asociadas a los movimientos como la Trasvanguardia italiana, los Nuevos Salvajes alemanes, la New image estadounidense o sus homónimos del contexto español, que trazaría una historia donde el realismo queda en los márgenes de la contemporaneidad.

Como respuesta ante esta situación, se articuló una operación de visibilización del realismo. El apoyo al realismo provino, particularmente, de las instituciones que en aquellos momentos dependían de instancias políticas madrileñas. Esto es, el Ayuntamiento de Madrid al que se unirían, en este esfuerzo, los medios de 
comunicación conservadores, como es el caso del diario ABC. No en vano, desde hacía tiempo, este periódico convocaba el premio de pintura Blanco y Negro, que se convirtió en referencia de la opción realista-figurativa, llegándose a celebrar la exposición de su XI edición en el Centro Cultural Conde Duque, dependiente del Ayuntamiento de Madrid en 1990, junto con, en el ámbito del dibujo, el Premio Penagos establecido en 1982 por la Fundación MAPFRE, en cuyas salas de exposiciones, abiertas desde diciembre de 1988, se acogerá la exposición desde su séptima convocatoria correspondiente al año de 1989. En relación con la citada fundación y otras, como la Fundación Central Hispano o la Fundación Caja Madrid, tendrán un papel en la ofensiva del realismo de aquella época.

Precisamente, fue en la sede madrileña de Caja Madrid, denominada La Casa del Monte, donde tuvo lugar una exposición, en 1992, que pretendía ser un auténtico manifiesto en pos de la visibilidad de las tendencias realistas. Bajo el título Otra realidad: compañeros en Madrid reunió la obra del grupo realista de Madrid a la que se uniría el trabajo de tendencia abstracta en conexión con el informalismo de Joaquín Ramo, Enrique Gran y Lucio Muñoz, quienes estarían en el círculo de amistad de aquéllos pero que, estilísticamente, se situarán en un contexto bien diferenciado. Su inclusión en esta exposición, de algún modo, legitimaba la defensa del realismo en el contexto del pluralismo frente a los agravios que, desde este entorno, se percibían provenientes de los diversos agentes (del ámbito de la práctica artística, la crítica, la teoría o de la política expositiva y de adquisiciones institucional) que situaban esta estética en los márgenes de la historia del arte contemporáneo. Por otra parte, esta exposición pretendía ser, en cierto modo, la continuación de otra celebrada bajo el título de La Escuela de Madrid, año y medio antes en la misma sala y con los mismos promotores; esto es la Fundación Caja Madrid y la Fundación Humanismo y Democracia, vinculada ideológicamente al Partido Popular. Se trataba con esta exposición de rescatar cierta herencia artística, aparentemente, menospreciada con la que poder establecer puentes con la generación representada en la exposición del grupo realista madrileño para, así, darles un lugar en la escena artística contemporánea en un intento de construir una narración historiográfica alternativa a la propuesta por otras instituciones. Julián Gállego leía la emergencia de varias exposiciones, en el contexto institucional público de Madrid, entre la que destacaba ésta, como una reacción frente al ninguneo de la tradición pictórica española, que incluía lo moderno y lo contemporáneo, asociada a la figuración:

Se diría que, aprovechando la calma que sus obras de remodelación imponen al Centro Reina Sofia, celoso paladín de las vanguardias internacionales, los artistas madrileños salieran en defensa de sus fueros y de un momento la pintura española que incluso los museos perecían olvidar, en aras de más abruptas novedades (Gállego, J. 1990, 31 de mayo, p. 141).

En el contexto del realismo madrileño se insistió, con una actitud beligerante desde comienzos de la década de los noventa, en la dificultad de visibilización de sus prácticas en el contexto institucional y, muy especialmente, en el Museo Nacional Centro de Arte Reina Sofía. En este sentido, con motivo de la exposición de los realistas Amalia Avia, Antonio López, María Moreno, Isabel Quintanilla, Daniel 
Quintero, José María Mezquita, Francisco López Hernández y Julio López Hernández, en la galería Marlborough de Londres en 1996, el diario El Mundo recogía unas declaraciones de algunos componentes de este grupo en las que se lamentaban sobre la política de dicho museo (Sierra, R. 1996, 19 de julio).

Sin embargo, el realismo contó con algunos de sus representantes más destacados en la exposición que el mencionado museo, dirigido entonces por Tomás Llorens, realizó en 1987 con el título de Naturalezas españolas (1940-1987), o en la selección que, para definir el arte moderno y contemporáneo español, hizo el propio Llorens y Calvo Serraller en la exposición del CARS El siglo de Picasso de 1988. Ya en tiempos de María Corral como directora del museo, coincidiendo con el estallido de la querella, se programaron dos grandes retrospectivas de artistas realistas, Carmen Laffón: bodegones, figuras y paisajes, en 1992 y, un año más tarde, Antonio López. Pintura, Escultura, Dibujo. Exposición Antológica.

En 1993, dará comienzo una serie de exposiciones retrospectivas sobre la obra de distintos artistas realistas, en un esfuerzo de las instituciones de arte municipales madrileñas por visibilizar, a modo de desagravio (Pulido, N. 1994, 29 de septiembre, p.62), las obras realizadas bajo la égida de esta corriente. La primera de esta sucesión de muestras será Eduardo Naranjo: retrospectiva 1954-1993, en el Centro Cultural de la Villa, y al año siguiente, en 1994 en esta misma institución, se verá Cristóbal Toral. Exposición antológica. En 1997 en idéntico espacio, coincidiendo con los últimos coletazos de la Querella, se organizará la muestra retrospectiva Amalia Avia. Exposición Antológica. El Centro Cultural Conde Duque se unirá a la causa del realismo, en 1994, con la exposición Realismos. Resulta de especial interés, en este caso, la meridiana confluencia de los intereses privados con la política expositiva del sector público. Tal circunstancia puede observarse en la naturaleza de esta exposición como prolongación del libro Realismos: Arte Español Contemporáneo (Mato Ansorena, J. \& Mato Ansorena, C. 1993), publicado por la galería madrileña Ansorena, conocida por su apuesta estética realista. Dicha obra, al igual que la subsecuente exposición, trataban de colocar al realismo en la escena artística contemporánea de la que se entendía había sido excluida. Se puede considerar Realismos como un verdadero manifiesto, en el contexto del intento de la primera mitad de la década de los noventa de rehabilitación de la figuración en el contexto de la tradición artística española.

A Realismos le sucederían, en el ámbito expositivo del Centro Cultural Conde Duque, dos retrospectivas del matrimonio realista Quintanilla-López: Isabel Quintanilla y Francisco López Hernández, y la retrospectiva, dedicada al hermano de este último, en la Sala de Exposiciones de Plaza de España de la Comunidad de Madrid bajo la denominación de Julio López Hernández. Exposición Antológica. Obra 1960-1995. Con motivo de estas muestras desde el semanario del diario $\mathrm{ABC}$, Laura Revuelta insistía en el maltrato al que habían sido sometidos: "Al igual que sucedió con otros artistas - digamos de corte realista, aunque no les agraden las etiquetas - fueron obviados durante largos años por los críticos y las galerías nacionales" (Revuelta, L. 1996, 31 de marzo, p. 34). 


\subsection{El punto álgido de la Querella}

Sería en torno a la citada antológica en el MNCARS de Antonio López cuando se visibilizarían, con una virulencia y una presencia en lo medial sin parangón, los argumentos de la Querella del realismo y la abstracción. Este conflicto se polarizó en las figuras de Antonio López y Antoni Tàpies. Precisamente, según la versión del diario $\mathrm{ABC}$, el origen de la polémica se situó en las declaraciones de Tapiès, a este mismo medio, en las que descalificaba el realismo. Sin negar que, efectivamente, gracias a la publicación de las opiniones de éste sobre el realismo - que al parecer eran la reedición de otras que formuló con motivo de la exposición Europalia 85 (Aberasturi, A. 1993, 21 de junio, p. 56) - , estalló el conflicto de manera pública. Si bien, no pueden pasarse por alto los antecedentes que aquí han sido expuestos y que prepararon el clima de enfrentamiento.

Conviene, antes de tratar los argumentos de Tàpies, examinar determinadas cuestiones que se produjeron los meses inmediatamente anteriores a la inauguración de la antológica de Antonio López en el Museo Nacional Centro de Arte Reina Sofía. En principio esta institución tenía programada la retrospectiva del pintor realista para el 27 de octubre de 1992, no pudiéndose llevar a cabo debido a la negativa de éste como medida de protesta y presión ante la afrenta que entendía se producía hacia la corriente estética que él representaba en la colección permanente del referido museo. Este no será el último de los episodios de la compleja relación de Antonio López con el Museo Nacional Centro de Arte Reina Sofía. En 2007, un año después de haber sido galardonado con el Premio Velázquez que se unía a los diversos reconocimientos institucionales de los que había sido objeto como la Medalla de Oro de Bellas Artes en 1983 y el Premio Príncipe de Asturias de las Artes en 1985, decidió una vez más no realizar una exposición programada, para el 2 de octubre de ese año, en dicho museo aplazándola sine die alegando, en esta ocasión, que necesitaba más tiempo para preparar convenientemente esta muestra, que no se ha llegado a realizar nunca.

Volviendo a los sucesos de 1992, en una carta dirigida, en septiembre, a su directora María Corral le expresó su renuncia a celebrar la exposición antológica acordada, en tanto no se reparara la situación de exclusión del realismo de los fondos del museo. Dicha carta, fue recogida por el diario El País (López, A. 1992, 12 de septiembre).

A raíz de la negativa de Antonio López, se inició una importante campaña mediática, en la órbita de la Querella que aquí se analiza, contra la selección de obras expuestas en el museo que la directora había realizado. Tras varias reuniones, que contaron con la intervención del Ministro de Cultura de la época, Jordi Solé Tura, Antonio López y María de Corral, se llegó a un acuerdo, basado en el compromiso del museo de completar su colección con obras realistas, por el que el pintor presentaría su muestra antológica en mayo de 1993. A pesar de este pacto, el pintor animó públicamente a la revitalización de la polémica en torno al realismo (Enriquez, A. 1993, 5 de febrero, p. 25), en los meses anteriores a su exposición. Esta actitud, quizá, se vio reforzada por su nombramiento, en enero de 1993, como académico de número en la sección de Pintura de la Real Academia de Bellas Artes de San Fernando de Madrid, y por un ascenso en su popularidad debido al estreno, por esas mismas fechas, de la película documental sobre su proceso de trabajo, que bajo el título El sol del membrillo, había realizado el director Víctor Erice. 
Una semana antes de la inauguración de su exposición antológica, en declaraciones a los diarios El País (García, A. 1993, 29 de abril, p.29) y ABC (Corral, P. 1993, 30 de abril, p. 28) Antonio López se reafirmaba en sus posturas pese a haber, finalmente, aceptado la propuesta del museo. Sorprende el carácter de permanente insatisfacción de este pintor en relación con la valoración del realismo, teniendo en cuenta los innumerables reconocimientos públicos institucionales de los que había sido objeto hasta esa fecha, y que culminaban en la exposición antológica que el Museo Nacional Centro de Arte Reina Sofía estaba a punto de dedicarle. Cierto es, sin embargo, que la presencia del realismo, con el que él estaba vinculado, en la colección de dicho museo no podía calificarse como extraordinaria, debido a numerosas causas, como tampoco lo eran otros planteamientos artísticos que nada tenían que ver con este tipo de estéticas.

Con motivo de la apertura de la XLV Bienal de Venecia, el 13 de junio de 1993, se publicó en el diario $\mathrm{ABC}$ la entrevista a Tàpies, seleccionado para mostrar su trabajo en el Pabellón español, donde se reprodujeron las afirmaciones de éste sobre el realismo, que encenderían la polémica más agria de la Querella. La situación en la que se produjeron estos comentarios venía precedida de otra disputa pública, alimentada fundamentalmente por los medios conservadores, en relación con la división de opiniones entre los miembros del patronato del Museu Nacional d'Art de Catalunya, acerca del proyecto escultórico que Tàpies había presentado para el Salón Oval de este museo consistente en un gran calcetín agujereado. El conflicto que se produciría a raíz de los argumentos esgrimidos por Tàpies puede bien inscribirse en una especie de nueva entrega de la celebérrima Querelle des Anciens et des Modernes. La línea discursiva central estaba íntimamente relacionada con una concepción progresiva, en un sentido historicista propio de la modernidad, del devenir del arte basado en la obsolescencia de las formas artísticas. La postura de Tàpies asociaba, sin explicitarlo, el realismo como opción estética del pasado, con el conservadurismo ideológico y con intereses exclusivamente de mercado. En este sentido, Tàpies responde, en la entrevista citada, a la pregunta sobre el resurgimiento del realismo, en aquellos años, en la pintura española que "(...) todo lo que se ha hecho en torno a este tipo de arte es una manipulación comercial y los museos se prestan incomprensiblemente a este juego" (Calderón, M. 1993, 11de junio, p. 37).

Vincula este protagonismo con ciertos entornos sociales asociados bien al poder del capital o a la cultura masiva: "Simplemente creo que es una pintura facilona, que gusta a los nuevos ricos y a la gente poco preparada y, por lo tanto, siempre tendrá cierto éxito" (Calderón, M. 1993, 11de junio, p. 37). En cierto modo la posición de Tàpies remite al marco excluyente vanguardista pero desde las formulaciones modernistas de carácter aristocrático, greenberianas tal vez, en lo relativo al arte mandatado históricamente. Esta postura le lleva a proponer, aparentemente a modo de provocación, la instauración de organismos de control de calidad de lo estético (Calderón, M. 1993, 11de junio, p. 37). Aludiendo a las obras realistas como productos caducados, vuelve sobre los planteamientos de la obsolescencia del arte en una interpretación progresiva de la historia del arte. Siguiendo este hilo discursivo parece claro que Tàpies considera que el realismo estaría situado en los márgenes del espacio donde el arte contemporáneo sucede, considerando que su representación en 
la colección del MNCARS, principal argumento del litigio del realismo con dicha institución, era más que suficiente.

La reacción del grupo realista no se hizo esperar y una semana más tarde en las páginas del mismo diario responderían a Tàpies. La réplica de los realistas procuró situar la problemática de la Querella en registros distintos a los propuestos por Tàpies en relación con el enfrentamiento de lo antiguo y lo moderno. De este modo, se produjo una actualización de los argumentos que viraron hacia el conflicto, más cercano históricamente, entre los defensores y detractores del pluralismo. En los textos publicados en respuesta a Tàpies, existe una voluntad común de ubicar las posiciones del realismo, fuera de la discusión ideológica, en el espacio de defensa del pluralismo de la escena artística contemporánea. No parece claro hasta qué punto dichos artistas estaban comprometidos en la defensa real de este marco, problemático en sí mismo, o se trataba más bien de un recurso instrumental, en gran medida inconsciente, para la extensión de los intereses reivindicativos del realismo. Las llamadas a una actitud pluralista pueden observarse en los diferentes textos publicados por los realistas como es el caso del de Julio López Hernández (López Hernández, J. 1993, 18 de junio, p. 37). El pluralismo también fue el eje central de la respuesta de Antonio López como se colige de sus palabras:

(...) aqui estoy escribiendo unas palabras en apoyo de algo que aparentemente todos deseamos: el derecho a vivir y a expresarnos desde nuestra individualidad. (...) A estas alturas del siglo XX y cuando tantos dogmas religiosos, políticos, éticos, se han venido abajo, sorprendentemente en el mundo de la creación artística, aparentemente tan libre, hay unos controles, una actitud restrictiva, un encogimiento triste y empobrecedor (López Hernández, J. 1993, 18 de junio, p. 37).

Ciertamente, Antonio López se expresa como un pluralista, dotando a esta posición de un cierto halo de superioridad ética en un contexto donde todos los conflictos sociales, políticos y estéticos se dan por solventados. En el resto de artículos (Avia, A. 1993, 18 de junio, p. 39; Muñoz Vera, G. 1993, 18 de junio, p. 38; Pita, G. 1993, 18 de junio, p. 38; Quetglás, M. 1993, 18 de junio, p. 38; Toral, C. 1993, 18 de junio, p. 39) que componen la referida respuesta del realismo, se insistió en los argumentos pluralistas y en el sempiterno lamento por la falta de atención dispensada por el mercado y la institución al realismo.

Es probable que el propio Tàpies se sintiera, a su vez, agraviado por el MNCARS, debido a la atención que en esos momentos recibía Antonio López y a pesar de haber realizado en este centro una exposición antológica en 1990, teniendo en cuenta la orientación contemporánea de este centro, donde su producción estaba enmarcada frente a la de éste cuyos planteamientos pertenecían, en su opinión, cuando menos a los márgenes. Con motivo de otra retrospectiva en dicho museo Tàpies deslizaba, en una entrevista realizada por El Cultural del diario El Mundo, lo que podrían ser los motivos de su polémica con el realismo, acaecida siete años antes: "Me complace que estas obras se muestren en una exposición madrileña, porque algunas veces se ha reivindicado desde la capital una especie de monopolio de la figuración" (Navarro Arisa, J. J. 2000, 5 de abril). 


\subsection{El final de la Querella}

A principios de 1994 se había apagado el encendido debate, al menos en lo referente a su dimensión medial que, por otra parte, fue el verdadero sustento del mismo. En los años sucesivos se pudo asistir a distintos fenómenos asociados con la Querella - principalmente las reiteradas reclamaciones de los realistas con motivo de la celebración de alguna de las exposiciones que trataban de rehabilitar la importancia de esa opción estética - cuya intensidad fue extinguiéndose según avanzaba la década de manera tal que, con el cambio de siglo, no quedaron evidencias de la misma. En 1993 la exposición antológica de Antonio López, en el Museo Nacional Centro de Arte Reina Sofía, se saldó con una enorme cantidad de visitas, alrededor de 325.000 , y algunos quisieron ver en este éxito popular el definitivo triunfo de las posiciones del realismo en el habitual juego de utilización de los números, del evento masivo a fin de cuentas, como instancia de legitimación de lo artístico. Sin embargo, y a pesar de la presión realizada desde otras instituciones, las demandas asociadas al primer plante al Museo Nacional Centro de Arte Reina Sofía de Antonio López nunca fueron atendidas en la medida que éste y el grupo al que estaba vinculado habían exigido, estando, aún en la actualidad, activas sus reivindicaciones pero ya sin el apoyo mediático-institucional. ¿Qué sucedió en el panorama artístico de la segunda mitad de la década de los noventa para que la querella se disolviera? A lo largo de la década de los noventa se puede entender que se produjo, de algún modo, un retorno de lo real, parafraseando a Foster (Foster, H. 2001), lo cual no significa una revitalización del realismo que hundía sus raíces en la tradición pictórica. Muy al contrario fueron otros modos de enfrentarse con la realidad, que ya habían fundamentado las apuestas estéticas de los nuevos realismos de las décadas de los cincuenta y sesenta, las que ahora reemergían. Por otra parte, el discurso del realismo madrileño, o ámbitos estéticamente afines, que defendían la centralidad de lo disciplinario quedó ampliamente rebasado por una situación que, en la escena española a partir fundamentalmente de los noventa, inició una época en la que la atención a las disciplinas, tradicionales o no, no resultarían determinantes en la definición de las producciones artísticas.

Cabría, del mismo modo, señalar como causa de la deflación de la querella el hecho de la pérdida, por parte del grupo realista, del apoyo tan meridiano que habían recibido, durante aquellos años de beligerancia, de las instituciones y de los medios afines. A pesar de la virulencia de su episodio más destacado, la querella tuvo un corto recorrido pero lo suficiente para desarrollar una operación, en el contexto de la política cultural madrileña, conducente a la atención reparativa, a través de las exposiciones antológicas de los realistas, de las pretendidas injusticias cometidas, por las instituciones de arte contemporáneo dependientes de otras instancias públicas o privadas, contra el realismo. 


\section{Referencias}

Aberasturi, A. (1993, 21 de junio). Tàpies y los nuevos ricos. $A B C$, p. 56.

Avery, M., Bishop, I., Bohrod, A., Bosa, L., Bouché, L., Burchfield, C., et al (1953,

Spring). Statement. Reality: A Journal of Artists' Opinions, Vol. 1, №. 1, p. 1.

Avery, M., Bishop, I., Bohrod, A., Bosa, L., Bouché, L., Burchfield, C., et al (1953, Spring). Letter to Museum of Modern Art. Reality: A Journal of Artists' Opinions, Vol. 1, No. 1, p. 2.

Avia, A. (1993, 18 de junio). Él se lo pierde. $A B C$, p. 39.

Baudelaire, C. (1995). El pintor de la vida moderna. Murcia: Colegio Oficial de Aparejadores y Arquitectos Técnicos.

Calderón, M. (1993, 11de junio), Tàpies: «El realismo es pintura facilona para nuevos ricos». ABC Cultural, p. 37.

Clair, J. (1998) La responsabilidad del artista. Madrid: La balsa de la Medusa, Visor.

Corral, P. (1993, 30 de abril). Antonio López inaugura el próximo martes su exposición en el CARS. $A B C$, p. 28.

Danto, A. C. (1999) Después del fin del arte. El arte contemporáneo y el linde de la historia. Barcelona: Paidós.

Enriquez, A. (1993, 5 de febrero). Antonio López defiende la necesidad de reabrir la polémica en torno al realismo. Diario 16, p. 25.

Foster, H. (1995). Contra el pluralismo, El Paseante, no 23-25, pp. 80-95.

Foster, H. (2001). El retorno de lo real. La vanguardia a finales de siglo. Madrid: Akal.

Fumaroli, M. (2008). Las abejas y las arañas. La Querella de los Antiguos y los Modernos. Barcelona: Acantilado.

Gállego, J. (1990, 31 de mayo). La Escuela de Madrid. ABC, p. 141.

García, A. (1993, 29 de abril). Antonio López: «El realismo sigue menospreciado». El País, p.29.

Greenberg, C. (2002). Arte y cultura. Ensayos críticos. Barcelona: Paidós.

d'Harnoncourt, R., Barr, A. H. \& Ritchie, A. C. (1953, 24 de abril). An Open Letter To "Reality" Magazine. Recuperado de http://www.moma.org/momaorg/shared/ pdfs/docs/press_archives/1711/releases/MOMA_1953_0041_39.pdf?2010

Hegel, G. W. F. (1989). Lecciones sobre la estética. Madrid: Akal.

Jameson, F. (1998). Teoría de la postmodernidad. Madrid: Trotta.

Jameson, F. (2000). Las semillas del tiempo. Madrid: Trotta.

Jameson, F. (2009). El debate entre realismo y modernismo. Reflexiones para concluir. Youkali. Revista crítica de las artes y el pensamiento, 7. Recuperado de http://www.youkali.net/Youkali7-7clasico-FredricJameson.pdf

Jauss, H. R. (1976). La literatura como provocación. Barcelona: Península.

Koselleck, R. (2004). historia/Historia. Madrid: Trotta.

Kuspit, D. (2006) El fin del arte. Madrid: Akal.

López, A. (1992, 12 de septiembre). «Querida María...». El País. Recuperado de http://www.elpais.com/articulo/cultura/LOPEZ/ ANTONIO /PINTOR/ CORRAL/_MARIA/MADRID/MADRID_MUNICIPIO/MUSEO_REINA_ SOFIA_MĀDRID/elpepicul/19920912elpepicul_10/Tes 
López Hernández, J. (1993, 18 de junio). La vieja soberbia de siempre. ABC, p. 37.

Lyotard, J. F. (1998). La condición postmoderna: Informe sobre el saber. Madrid: Cátedra.

Mato Ansorena, J. \& Mato Ansorena, C. (Dir.) (1993). Realismos: arte español contemporáneo, Madrid: Mato Ansorena, D.L.

Muñoz Vera, G. (1993, 18 de junio). Un blanco tentador. $A B C$, p. 38.

Navarro Arisa, J. J. (2000, 5 de abril). Tápies histórico. El Cultural. Recuperado de http://www.elcultural.es/version_papel/ARTE/3386/Tapies_historico

Pita, G. (1993, 18 de junio). ¿Quién manipula? $A B C$, p. 38.

Pulido, N. (1994, 29 de septiembre). El mundo de la cultura rinde homenaje a Cristóbal Toral en su gran antológica. $A B C$, p.62.

Quetglás, M. (1993, 18 de junio). Tàpies y los comités de limpieza espiritual. $A B C$, p. 38.

Revuelta, L. (1996, 31 de marzo). Francisco López Hernández e Isabel Quintanilla. Blanco y Negro, p. 34.

Sharrer, H. (1953, Spring). Humanism in Art. Reality: A Journal of Artists' Opinions, Vol. 1, No. 1, p. 4.

Sierra, R. (1996, 19 de julio). Los realistas españoles vuelven a Londres 23 años después de que la Marlborough los juntara. El Mundo. Recuperado de http://www. elmundo.es/papel/hemeroteca/1996/06/19/cultura/

Sloterdijk, P. (2003). Crítica de la razón Cínica. Madrid: Siruela.

Swift, J. (2005). Batalla entre libros antiguos y modernos. Alicante: Eduardo de Blas.

Toral, C. (1993, 18 de junio). El berrinche de Tàpies. $A B C$, p. 39. 